\title{
CORONARY INTERVENTION IN A PATIENT WITH INVASIVE BLADDER CARCINOMA: ROLE OF MULTIDISCIPLINARY APPROACH FOR HIGH RISK PATIENTS
}

\author{
ABDUL WADUD CHOWDHURY ${ }^{1}$, MA SALAM ${ }^{2}$, NAIMUL HAQUE ${ }^{3}$, AMITAVSAHA ${ }^{4}$, \\ ZIAUR RAHMAN CHOWDHURY ${ }^{5}$
}

\section{Introduction:}

Bladder cancer is the second most common malignancy of the genitourinary system. Several types of carcinoma arise on the urothelial surface, the most common type being transitional cell carcinoma (TCC). ${ }^{1}$ The incidence of TCC in the bladder in the UK is 45 cases per 100,000 population. ${ }^{2}$ Painless haematuria is the most common presenting symptom in $85-90 \%$ of patients with bladder cancer, ${ }^{3}$ although recurrent urinary tract infection \& obstructive symptoms may occur. Physical examination is usually unremarkable except in very advanced disease. Investigation of haematuria as well as cytological examination of urine for malignant cell and renal imaging study usually identifies the tumour. Treatment of TCC of bladder primarily involves surgery, chemotherapy or radiotherapy as needed. ${ }^{3}$ Radical cystectomy for TCC in elderly carries adverse prognosis because of associated co-morbid conditions like hypertension, diabetes, chronic obstructive pulmonary disease (COPD) \& ischaemic heart disease (IHD). However, close co-operation between different disciplines can make radical curative surgery a viable alternative even in these high-risk groups.

\section{Case History:}

Md. Ismail, a 68 years old hypertensive, smoker patient, suffering from chronic obstructive pulmonary disease (COPD) had suffered an inferior wall myocardial infarction 3 years back. Recently he was suffering from dysuria, haematuria, class III effort angina and shortness of breath (NYHA class III) for the last 1 to 2 months. Suspecting a case of urinary bladder neoplasm after primary evaluation, he underwent Trans Urethral Resection of Bladder Tumour (TURBT) on $3^{\text {rd }}$ August 2007 in a hospital in Chittagong. On $2^{\text {nd }}$ postoperative day, he suddenly developed acute left ventricular failure (LVF), which was managed conservatively. After initial recovery patient was referred to Dhaka for further treatment, as biopsy of the bladder tumour revealed high-grade muscle invasive papillary urolethial carcinoma. ultrasonogram (Fig.-1) and CT scan of pelvis showed

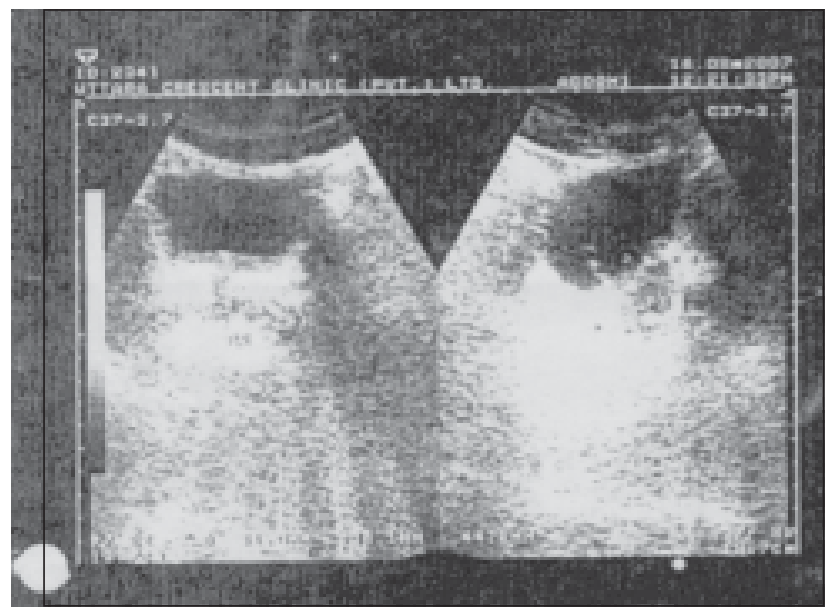

Fig.-1: Ultra sonogram showing irregular diffuse thickening of whole bladder wall with small polypoidal projection from left lateral wall.

malignancy had not spread beyond bladder wall. A bone scan by ${ }^{99 \mathrm{~m}} \mathrm{Tc}$ revealed normal study. So a curative strategy like radical cystectomy with either

1. Associate Professor, Department of Cardiology, National Institute of Cardiovascular Diseases and Hospital, Dhaka.

2. Professor, Department of Urology, Bangabandhu Sheikh Mujib Medical University, Dhaka

3. Professor, Department of Anesthesia, National Institute of Cardiovascular Diseases and Hospital, Dhaka

4. Post Graduate Trainee, Department of Medicine, National Institute of Chest Diseases and Hospital, Dhaka

5. Medical Officer, Department of Hepatology, Bangabandhu Sheikh Mujib Medical University, Dhaka

Correspondence : Dr. Abdul Wadud Chowdhury, E-mail: drwadud@hotmail.com 
urinary diversion or orthotopic ileal neobladder formation was planned by the urologist. But at preanesthetic checkup, he was found to have COPD with OMI (Inferior), anterolateral hypokinesia, mitral regurgitation (grade- I) and severe LV systolic dysfunction (ejection fraction 30\%). So the concerned anesthetist declared him unfit for radical surgery. The patient was then referred to the cardiologist. He underwent coronary angiogram (CAG), which revealed left main coronary artery had $30 \%$ stenosis with fairly normal Left anterior discending (LAD) \& Left circumflex (LCX). RCA was dominant vessel with total occlusion in mid RCA (Fig.-2). Posterior descending artery and post-left ventricular branch (PLV) of RCA was retro-filled from left system. The occluded RCA was opened up and a $3.0 \mathrm{X} 25 \mathrm{~mm}$ bare metal stent was implanted (Fig.-3).

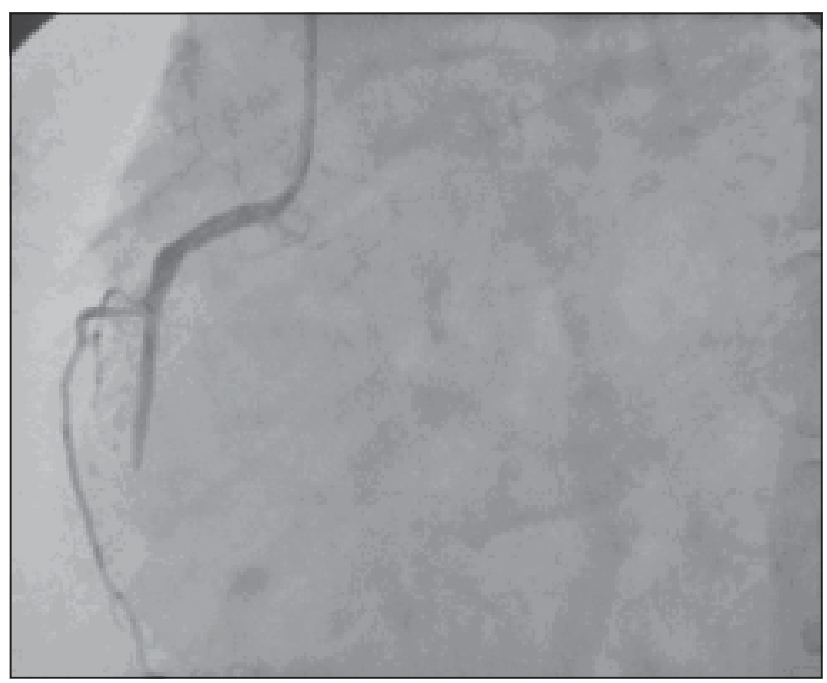

Fig.-2: CAG showing RCA totally occluded in mid segment

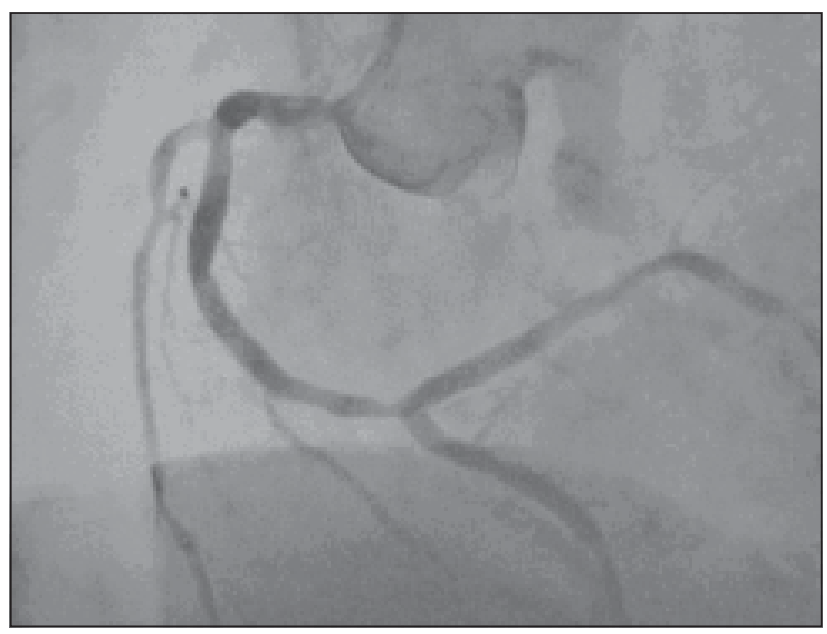

Fig.-3: After PTCA + stenting the opened up RCA with big PDA \& PLV branch with good flow.
The result was a gratifying TIMI III flow into big PDA and PLV branch. Patient was followed up for 3 weeks. A follow up echocardiography showed reduction of LV size (LVIDd $53 \mathrm{~mm}$, down from $62 \mathrm{~mm}$ \& LVIDS $42 \mathrm{~mm}$, down from $52 \mathrm{~mm}$ ) and improvement of $\mathrm{LV}$ systolic function (EF increased from $30 \%$ to $42 \%$ ). He was then referred back to the urologist for planned surgery. The patient underwent radical cystectomy with orthotopic ileal neobladder formation on 24th September 2007. With a lower midline incision the bladder was reached, distal 1/3rd of both ureters \& dorsal venous plexus were dissected up to prostatic urethra. Both iliac and obturator lymph nodes sampling were done. The whole bladder was taken out including lower end of the both ureters. Then an $18 \mathrm{~cm}$ ileal segment with vascular pedicles was dissected, detubularized and a conical neobladder was fashioned. The ileum was repaired by end-to-end anastomosis. In the neobladder, both ureters were reimplanted keeping two 6 Fr DJ stent inside. Prior to surgery antiplatelets were stopped for four days and restarted on 3rd postoperative day. However on 4th postoperative day, patient suddenly developed compressive chest pain, respiratory distress with hypotension. He was then immediately shifted to a cardiac hospital under the cardiologist. Patient's troponin-I rose slightly to $1.32 \mathrm{ng} / \mathrm{ml}$. With conservative management, he recovered quickly without any complication. Meanwhile the biopsy reports of lymph nodes, ureteric margin (both sides), resected part of the bladder, prostatic tissue- all were found to be free of malignancy. After a week, patient went back to Chittagong on 2nd week of October. He remained under close follow up of both urologist and cardiologist. The stents in the ureters were taken out later. On the last follow up nearly 1 year later, the patient is found to be free of malignancy recurrence. His cardiac status is also stable.

\section{Discussion:}

$98 \%$ of primary bladder cancers are epithelial malignancies, with the majority being TCC (90\%). ${ }^{3}$ Haematuria is the hallmark of bladder cancer either alone or associated with irritative symptoms (frequency, urgency \& dysuria). ${ }^{4}$ The tumors are traditionally classified into papillary and nonpapillary types. Nonpapillary tumors are considered malignant. About $80 \%$ of all bladder TCCs are low-stage superficial papillary neoplasm (multifocal in a third), which become invasive in 10-20\% of cases. These invasive tumors are almost always solitary. Early lymphatic 
invasion and bladder wall infiltration are associated with a poor prognosis. ${ }^{5}$

Treatment and prognosis of carcinoma depend on the staging and grading of the tumour. Superficial bladder tumours are treated by transurethral resection or local diathermy with follow up check cystoscopy and cytological examination of urine. Bladder instillation of doxorubicin, mitomycin \& thiotepa is used for recurrent tumours, as is instillation of BCG. Invasive bladder tumours are treated with radical cystectomy in patients under 70 years and radical radiotherapy in those over 70 years with salvage cystectomy for recurrence. ${ }^{6}$ However, bladder cancer has the highest recurrence rate of any malignancy. ${ }^{7}$ The 5 years survival rate varies from $50-60 \%$ in those with superficial tumours to $20-30 \%$ for those with deep muscle invasion. ${ }^{2}$ So early diagnosis is very much important as prognosis depends upon invasion. But it is often very difficult to treat bladder carcinoma in advanced age due to other comorbid conditions like hypertension, diabetes, IHD, heart failure, COPD etc. These comorbid conditions make the surgical procedure quite difficult with increased risk of fatal outcome. In our case this 68 years old hypertensive, COPD patient had OMI (inferior) with severe LV systolic dysfunction. Initially he was declared unfit for radical surgery by concerned anesthetist. However PTCA \& stenting of occluded RCA of this patient helped him to improve his cardiovascular performance before undergoing surgical intervention. The initial success is maintained at 1 year follow up, thus making the whole endeavor a very successful one. This case study also highlights that close interdisciplinary approach can enable many patients to undergo curative surgery who otherwise would have been left on palliative treatment alone.

\section{Conclusion:}

Bladder carcinoma (TCC) is not a rare disorder in our population. Surgical intervention is mandatory for bladder carcinoma. Many comorbid conditions like IHD, HTN, DM, COPD and heart failure increase risk of surgical fatal outcome in advanced age. However coronary intervention in selective cases of IHD is justifiable \& may benefit many patients who would otherwise be declared unfit for radical curative surgery. Interdisciplinary approach is therefore should be the key to achieve such successful outcome.

\section{References:}

1. Hudson MA, Herr HW. Carcinoma in situ of the bladder. J Urol. 1995; 153 (3 Pt 1): 564-72.

2. Goddard J, Turner AN, Cumming AD, Stewart LH. Kidney and urinary tract disease. In: Boon NA, Colledge NR, Walker BR, Hunter JAA, editors. Davidson's Principles and Practice of Medicine. 20 $0^{\text {th }}$ edi. Philadelphia: Churchill Livingstone; 2006: 455518.

3. Stoller ML, Carroll PR. Urology. In: Tierney LM, Mcphee SJ, Papadakis MA, editors. Current Medical Diagnosis \& Treatment. $45^{\text {th }}$ edi. USA: McGraw-Hill; 2006: 931-73.

4. Salam MA. Principles \& Practice of Urology A Comprehensive Text. $1^{\text {ST }}$ edi. Bangladesh: MAS publication 2002.

5. Maletic V, Cerovic S, Lazic M, Stojanovic M, Stevanovic P. Synchronous and multiple transitional cell carcinoma of the bladder and urachal cyst. Int $J$ Urol 2008; 15(6): 554-6

6. Yaqoob M. Renal disease. In: Kumar P, Clark M, editors. Kumar and Clark Clinical Medicine. $6^{\text {th }}$ edi. Philadelphia: WB Saunders; 2005: 605-87.

7. Morey SS. American Urological Association issues guidelines on the management of bladder cancer. Am Fam Physician 2000; 61(12): 3734- 36. 